\title{
PROPERTIES OF FUSION-WELDED JOINTS ON HIGH-STRENGTH TITANIUM ALLOY T110
}

\author{
S.V. AKHONIN ${ }^{1}$, V.Yu. BELOUS ${ }^{1}$, S.L. ANTONYUK ${ }^{2}$, I.K. PETRICHENKO ${ }^{1}$ and R.V. SELIN ${ }^{1}$ \\ ${ }^{1}$ E.O. Paton Electric Welding Institute, NASU \\ 11 Bozhenko Str., 03680, Kiev, Ukraine. E-mail: office@paton.kiev.ua \\ ${ }^{2} \mathrm{SE}$ «Antonov» \\ 1 Akademik Tupolev Str., 03062, Kiev, Ukraine. E-mail:lavrenko@antonov.com
}

\begin{abstract}
At present time, welding of high-strength titanium alloys can be performed using arc, electron beam in vacuum (EBW) and laser beam. There are successful examples of application of combined laser-arc process for performance of welded joints of titanium alloys. Negative effect of thermal cycle of EBW and laser welding on properties of series of alloyed titanium alloys is indicated in some cases. Aim of the present work lied in investigation of effect of different methods of welding and filler metal on mechanical properties and structure of welded joints by the example of titanium alloy T110. It is shown that high-strength titanium alloy T110 differs in good weldability in performance welded joints by EBW, full penetration argon-arc tungsten-electrode welding, argon-arc tungsten-electrode welding over the flux layer and laser-arc welding. SP-15 grade wire is reasonable for application as filler for argon-arc welding of T110 alloy. If welding without filler material is used, argon-arc tungsten-electrode welding over the flux layer provides the highest values of impact toughness of weld and HAZ metal. 8 Ref., 2 Tables, 3 Figures.
\end{abstract}

$\boldsymbol{K} \boldsymbol{e} \boldsymbol{y} \boldsymbol{w} \boldsymbol{o} \boldsymbol{r} \boldsymbol{d} \boldsymbol{s}:$ titanium alloys, T110, argon-arc welding, properties, laser welding, flux

Titanium alloys are characterized by high strength, heat resistance at moderate temperatures and corrosion resistance in the most aggressive media. Due to such properties they find application during manufacture of critical structures in aircraft and engine construction, chemical and other branches of industry. Today more and more attention is focused on expansion of application of welded structures and assemblies from high-strength titanium $\left(\sigma_{t} \geq 1100 \mathrm{MPa}\right)$.

Welding is one of the most widespread technological processes at development of complex parts and assembles. Therefore, weldability of titanium alloy is an important factor determining relevance of its application.

However, weldability of current highstrength titanium alloys, application of which could provide the maximum reduction of structure weight, is significantly worse than of lowalloyed alloys. Some high-strength steels are even inferior to them in this index.

The E.O. Paton Electric Welding Institute together with SE «Antonov» developed new high-strength titanium alloy $\mathrm{T} 110$ of $\mathrm{Ti}-\mathrm{Al}-\mathrm{Mo}^{-}$ $\mathrm{V}-\mathrm{Nb}-\mathrm{Fe}-\mathrm{Zr}$ system, containing the following alloying elements, wt.\%: 5.0-6.0 Al, 3.5-4.8 Nb, 0.8-1.8 Mo, 0.8-2.0 V, 1.5-2.5 Fe and 0.3-
$0.8 \mathrm{Zr}[1,2]$. Developed alloy exceeds VT22 and VT23 alloys on its service characteristics.

At present time, welding of high-strength titanium alloys can be performed by arc, electron beam in vacuum and laser beam. Arc welding allows changing chemical composition of weld metal and has such advantages as cheap and simple equipment. EBW and laser welding differ in high energy concentration in a heating spot and, respectively, high penetrability and efficiency. However, feeding of filler metal at that is complicated.

Negative effect of thermal cycle of EBW and laser welding on properties of series of alloyed titanium alloys VT23 and VT22 [3] is marked in some cases. It is concerned with high rates of heating and cooling of weld and HAZ metal. There are successful examples of application of combined laser-arc process in performance of welded joints from titanium alloys [4]. Therefore, study of effect of different methods of welding on mechanical properties and structure of welded joints from high-strength titanium alloy T110 seems to be reasonable.

Aim of the present work lied in study of effect of different methods of welding and filler metals on mechanical properties and structure of welded joints by the example of alloy T110.

Properties of T110 welded joints 7 and $13 \mathrm{~mm}$ thick made by different methods were investi- 


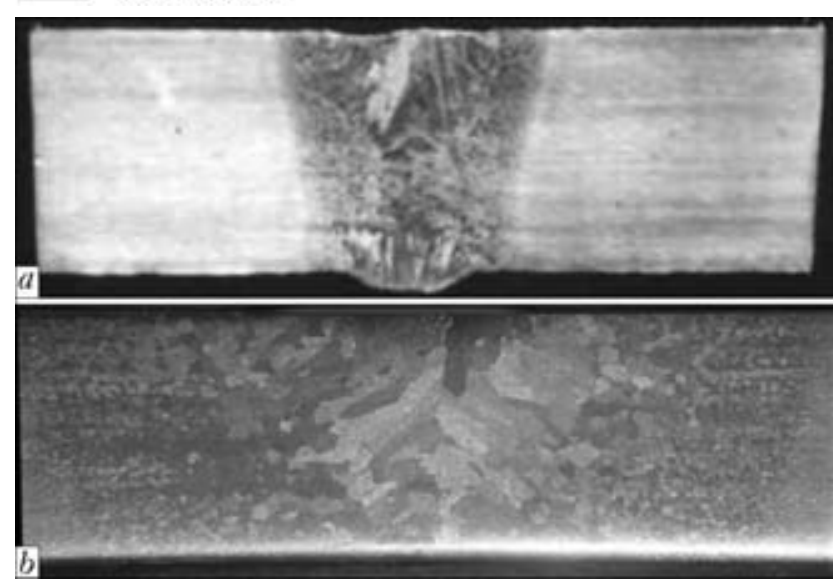

Figure 1. Transverse macrosections of EB- $(a)$ and TIG welded (b) joint from titanium alloy $\mathrm{T} 110$ of $7 \mathrm{~mm}$ thickness

gated in course of works. Mechanical properties of the base metal are given in Table 1 .

Plates of T110 alloy of $7 \mathrm{~mm}$ thickness were welded by EBW, full penetration argon-arc tungsten-electrode (TIG), argon-arc tungsten-electrode welding over the flux layer (A-TIG) [5] and groove argon-arc tungsten-electrode welding (groove TIG). In the latter case alloyed wire of SP-15 grade ( $\mathrm{Ti}-4.5 \mathrm{Al}-2.5 \mathrm{Mo}-2.5 \mathrm{~V}-3.5 \mathrm{Nb}-1.5 \mathrm{Zr})$ [6] was used as a filler. It can be used for welding of highstrength titanium alloys VT23 and VT22 [7].

TIG welding of plate $7 \mathrm{~mm}$ thick was carried out in automatic mode by laboratory welding head applyinge power source the ESAB ARISTO500. EBW was performed using UL-144 unit, equipped with ELA $60 / 60$ power source. Weld-

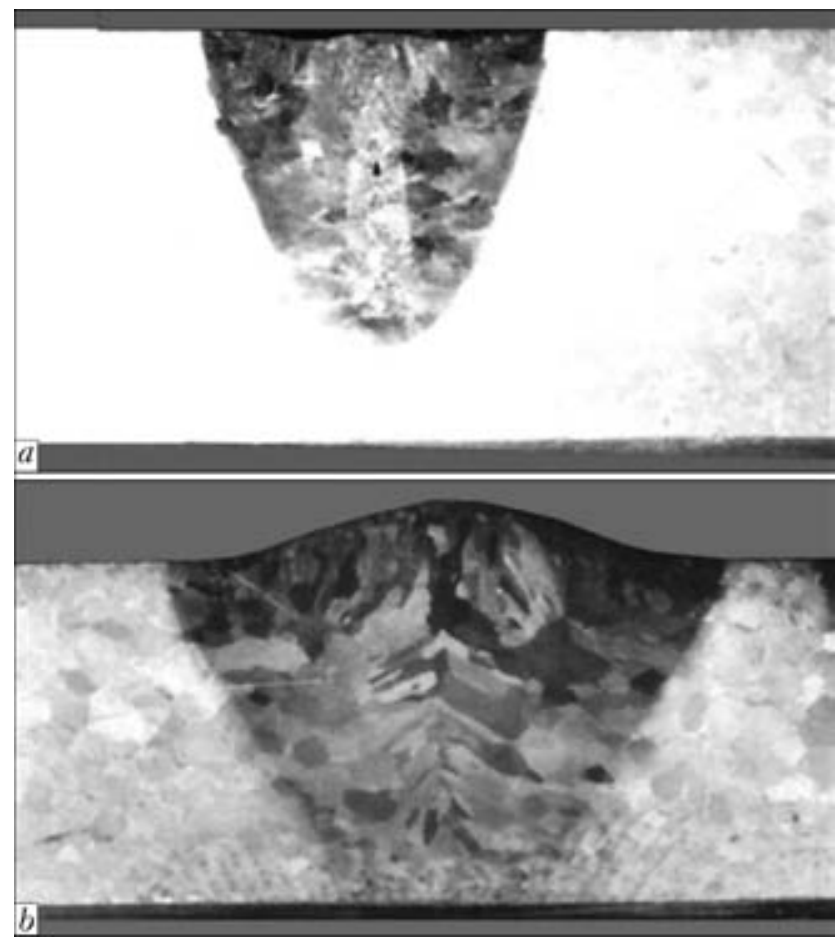

Figure 2. Transverse macrosections of welded joint from titanium alloy T110 of $13 \mathrm{~mm}$ thickness made by laser $(a)$ and laser-arc $(b)$ welding with equal laser beam power
Table 1. Mechanical properties of titanium alloy T110

\begin{tabular}{||c|c|c|c||}
\hline \hline BM thickness, $\mathrm{mm}$ & $\sigma_{\mathrm{t}}, \mathrm{MPa}$ & $\sigma_{0.2}, \mathrm{MPa}$ & $K C V, \mathrm{~J} / \mathrm{cm}^{2}$ \\
\hline 7 & 1190 & 1150 & 31 \\
\hline 13 & 1130 & 999 & 38 \\
\hline
\end{tabular}

ing of metal by A-TIG method was made using flux of ANT-25A grade [8]. T110 titanium plates $13 \mathrm{~mm}$ thick were welded by laser-arc method. Laser welding was used for surfacing of T110 alloy plates of $13 \mathrm{~mm}$ thickness. Laser and laserarc welding were carried out using laser unit DY 044 (Nd:YAG laser, wave length $1.06 \mu \mathrm{m}$ ) on scheme, according to which tungsten electrode is positioned before laser beam and the laser beam itself comes into tail part of the weld pool [4]. At that, welding rectifier VDU-601 was used as welding arc power source.

The examples of performed joints are shown in Figures 1 and 2.

Metal of welds, made by EBW, consists of transformed equiaxed $\beta$-grains, inside which uniform decomposition of solid solution with precipitation of disperse colonies of particles of secondary $\alpha$-phase is observed. The grains of former $\beta$-phase is finer in the near-weld zone, that indicates lower heat input in accumulative re-crystallization. Size of the polyhedral equiaxed grains reduces with increase of distance from the fusion zone to the base metal. EB-welded joints of T110 alloy, as well as welded joint of commercial titanium alloys of similar type, have high strength, insufficient ductility and impact toughness. Therefore, in order to increase these characteristics the welded joints of T110 alloy, made by EBW, should be annealed.

Dendrite structure (Figure 3, $a$ ) is well-observed in the weld of T110 alloy, made by laser welding. Primary $\beta$-grains, elongated in a heat sink direction, are observed on its background. Metastable $\beta$ - and $\alpha^{\prime} / \alpha^{\prime \prime}$-phases are registered in the metal of weld, made by laser welding, and substructure is present in the weld grains.

Study of microstructure of welded joints from titanium alloy allowed making a conclusion that the weld metal, obtained only using laser welding, has higher internal stresses. It is indirectly indicated by presence of multiple etching pits along the fusion line on transverse microsections, which are etched in the places of emergence of dislocation accumulations on the surface. Area of coarse grain is absent in HAZ metal of the welded joints, made by laser welding, whereas it is present in HAZ metal of the welded joints, performed by laser-arc welding. No substructure 


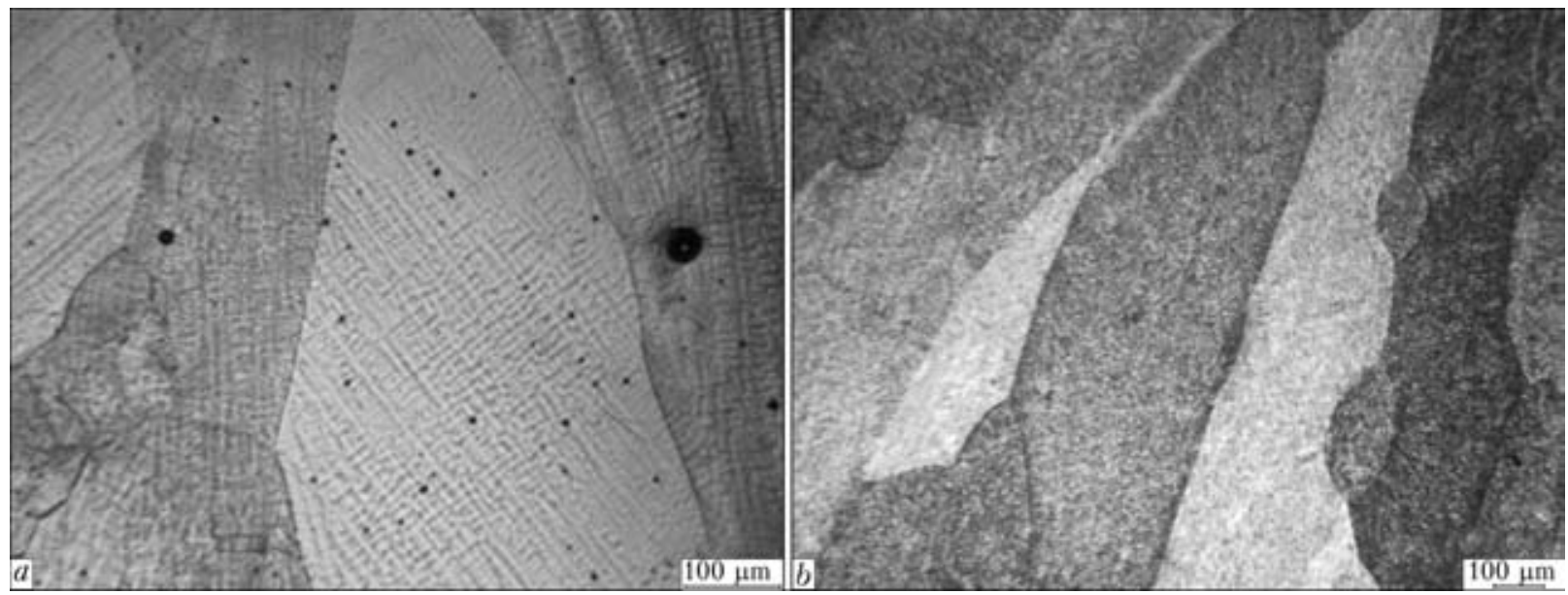

Figure 3. Microstructure of metal of T110 alloy weld, made by laser $(a)$ and laser-arc $(b)$ welding

was observed neither in weld nor in HAZ metal of the welded joint, made by laser-arc welding, in contrast to the welded joint from T110 alloy, performed by laser welding. The microstructure was more uniform and homogeneous (Figure 3, $b)$. Etching of section of the welded joint, made by laser-arc welding, in the same agent and during the same time as the section of the welded joint, performed by laser welding, promoted no etching pits. Probably, it can be related with lower level of welding stresses in laser-arc welding than in laser welding.

Microstructure of the arc-welded joints has virtual no difference from microstructure of the EB-welded joints. Thus, metal of single-pass welds and near-weld zones of the joints, made by full penetration TIG method, has typical lamellar structure of $\beta$-transformed grains, where finer precipitates of tertiary $\alpha$-phase are noticed between coarser $\alpha$-phase plates. Areas with partially transformed $\beta$-phase and $\alpha$-fringe on the $\beta$-grain boundaries are observed in separate grains as in the welds, made by EBW. Primary globular $\alpha$-phase is observed inside the grains in spite of indicated structural elements in HAZ metal areas adjacent to the base metal. Size of structural elements is a common distinction of microstructure of the joints, made by arc welding. They, as a rule, coarser and that, probably, explains a relatively low level of strength of the arc welds (Table 2).

The EB- and laser-welded joints have the zone (fusion and heat-affected) with significantly less structural changes in comparisons with the joints, made by tungsten electrode. Such structural difference should have positive effect on conditions of plastic strain in process of loading. It is indicated by analysis of places of fracture of welded specimens after the mechanical tests. Typical place of fracture of EB-welded joints is the base metal and in TIG welding it is the weld. The joints, made by laser-arc welding, typically fracture in the weld, and joints, performed by laser, failure in the base metal.

Comparison of the penetration depth during laser-arc and laser welding, received using the mode with similar laser beam parameters, showed double increase in penetration depth (see $\mathrm{Fi}^{-}$ gure 2) at constant laser beam power. Welded joints from T110 alloy, made by EBW and laser welding, have higher strength and insufficient impact toughness (see Table 2).

High impact toughness of HAZ metal should be noted in the A-TIG-welded joints and in laser-arc welding. The highest impact toughness is in the joints, performed by multi-pass groove TIG welding using filler wire SP-15, including lower content of alloying elements in comparison with the base metal. The weld metal, made by laser welding, has the lowest impact toughness. Strength of the welded joints of T110 alloy, made by laser and laser-arc welding, is $2-4 \%$ higher than the strength of the base metal, that is explained by presence in the weld metal of dendrite structure, typical for cast weld metal.

Table 2. Mechanical properties of as-welded joints from titanium alloy T110 made by different methods

\begin{tabular}{||l|c|c|c|c||}
\hline \multirow{2}{*}{ Welding method } & \multirow{2}{*}{$\begin{array}{c}\text { Metal } \\
\text { thickness, } \\
\text { mm }\end{array}$} & \multirow{2}{*}{$\sigma_{\mathrm{t}}, \mathrm{MPa}$} & \multicolumn{2}{|c|}{$\begin{array}{c}\text { Impact toughness } \\
K C V, \mathrm{~J} / \mathrm{cm}^{2}\end{array}$} \\
\cline { 4 - 6 } & 7 & 1140 & $\begin{array}{c}\text { Weld } \\
\text { metal }\end{array}$ & $\mathrm{HAZ}$ \\
\hline EBW & 7 & 1118 & 11 & 10 \\
\hline Full penetration TIG & 7 & 1030 & 20 & 12 \\
\hline Groove TIG & 7 & 1120 & 18 & 20 \\
\hline A-TIG & 13 & 1131 & 6 & 13 \\
\hline Laser & 13 & 1180 & 15 & 23 \\
\hline Laser-arc & \multicolumn{3}{|l}{} \\
\hline
\end{tabular}


Thus, the results of performed investigations indicate a good weldability of alloy T110 independent on method of welding.

\section{Conclusions}

1. High-strength titanium alloy T110 differs in good weldability during performance of welded joints using EBW, full penetration TIG, A-TIG and laser-arc welding.

2. As-welded joints, made by EBW, have the strength equal the base metal, and strength of the welded joints, performed by arc welding, makes not less than $90 \%$ of strength of alloy itself. Heat treatment can be used in order to increase the level of mechanical properties of T110 alloy welded joints.

3. Application of SP-15 grade wire as a filler material is reasonable for TIG welding of T110 alloy.

4. Laser-arc welding allows receiving the welded joints from high-strength titanium alloy T110 with wider complex of mechanical characteristics and lower internal stresses in comparison with laser welding. HAZ of the welded joints, made only by laser welding, has no coarse grain area, that can results in reduction of HAZ metal impact toughness. Coarse grain area is present in HAZ of the welded joints, made by laser-arc welding.
5. A-TIG welding provides for the maximum values of impact toughness of weld and HAZ metal on T110 alloy without filler material application.

1. Zamkov, V.N., Topolsky, V.P., Trygub, M.P. et al. High-strength titanium alloy. Pat. 40087 Ukraine. Publ. 16.06.2003.

2. Antonyuk, S.L., Zamkov, V.N., Topolsky, V.F. et al. (2003) Investigation of mechanical properties of cast semi-products of experimental titanium alloy T110. Advances in Electrometallurgy, 3, 27-30.

3. Paton, B.E., Shelyagin, V.D., Akhonin, S.V. (2009) Laser welding of titanium alloys. The Paton Welding J., 7, 30-34.

4. Shelyagin, V.D., Khaskin, V.Yu., Akhonin, S.V. et al. (2012) Peculiarities of laser-arc welding of titanium alloys. Ibid., 12, 32-36.

5. Gurevich, S.M., Zamkov, V.N., Blashchuk, V.E. et al. (1986) Metallurgy and technology of welding of titanium and its alloys. Kiev: Naukova Dumka.

6. Gurevich, S.M., Zamkov, V.N., Kushnirenko, N.A. et al. (1980) Selection of filler material for welding of $(\alpha+\beta)$-titanium alloys. In: Actual problems of welding of non-ferrous metals. Kiev: Naukova Dumka, 314-320.

7. Zamkov, V.N., Topolsky, V.F., Tyapko, I.K. et al. (1993) Influence of heat treatment on serviceability of VT23 alloy welded joints. Avtomatich. Svarka, 4, 25-27.

8. Gurevich, S.M., Zamkov, V.N., Prilutsky, V.P. et al. Welding flux. USSR author's cert. 439363. Publ. 15.08.74

Received 28.10.2013 